\title{
Oral supplementation with areca-derived polyphenols attenuates food allergic responses in ovalbumin-sensitized mice
}

\author{
Chia-Chi Wang ${ }^{1}$, Yu-Ru Lin², Mei-Hsiu Liao ${ }^{3^{*}}$ and Tong-Rong Jan ${ }^{2^{*}}$
}

\begin{abstract}
Background: Arecae semen, the dried slice of areca nuts, is a traditional Chinese medicine used to treat intestinal parasitosis, rectal tenesmus and diarrhea. Areca nuts contain a rich amount of polyphenols that have been shown to modulate the functionality of mast cells and T cells. The objective of this study is to investigate the effect of polyphenol-enriched areca nut extracts (PANE) against food allergy, a T cell-mediated immune disorder.
\end{abstract}

Methods: BALB/c mice were left untreated or administered with PANE $(0.05 \%$ and $0.1 \%)$ via drinking water throughout the entire experiment. The mice were sensitized with ovalbumin (OVA) twice by intraperitoneal injection, and then repeatedly challenged with OVA by gavage to induce food allergic responses.

Results: PANE administration attenuated OVA-induced allergic responses, including the occurrence of diarrhea and the infiltration and degranulation of mast cells in the duodenum. The serum level of OVA-specific IgE and the expression of interleukin- 4 in the duodenum were suppressed by PANE treatment. In addition, PANE administration induced $\mathrm{Gr}-1^{+}, \mathrm{IL}-10^{+}$and $\mathrm{Gr}-1^{+} \mathrm{IL}-10^{+}$cells in the duodenum.

Conclusion: These results demonstrate that oral intake of areca-derived polyphenols attenuates food allergic responses accompanied with a decreased Th2 immunity and an enhanced induction of functional myeloid-derived suppressor cells.

Keywords: Areca Nut, Food Allergy, Mast Cell, Myeloid-derived Suppressor Cells, Ovalbumin, Polyphenol

\section{Background}

Areca catechu Linn., a member of the Palmaceae family widely cultivated in South-Asian countries, is a folk medicine employed to ameliorate symptoms of gastrointestinal inflammation, dysentery and diarrhea [1,2]. Dried areca nuts, including its slices (Arecae semen) and pericarp (areca peel; $\mathrm{Da} \mathrm{Fu} \mathrm{Pi),} \mathrm{are} \mathrm{traditional} \mathrm{Chinese} \mathrm{medicines}$ used to treat distended abdomen and intestinal parasitosis, tenesmus and diarrhea $[1,3]$. Although this herb has a long history of medicinal use, limited evidence is available to substantiate its claimed pharmacological effects.

\footnotetext{
* Correspondence: michelle@iner.gov.tw; tonyjan@ntu.edu.tw

${ }^{3}$ Radiopharmaceuticals Production and Marketing Center, Institute of Nuclear Energy Research, No. 1000 Wenhua Road, Jiaan Village, 325, Longtan Township, Taoyuan, Taiwan

2Department and Graduate Institute of Veterinary Medicine, School of Veterinary Medicine, National Taiwan University, No. 1, Section 4, Roosevelt Road, 106 Taipei, Taiwan

Full list of author information is available at the end of the article
}

Areca nuts contain alkaloids, carbohydrates, crude fiber, fats, proteins and polyphenols that are structurally similar to grape seed- and apple-derived procyanidins [4-6]. Polyphenols have been shown to exhibit a broad spectrum of biological activities, including antioxidant, antiinflammatory, anti-allergic and immunomodulatory effects [7-9]. Accumulating evidence suggests that areca nuts possess a variety of potential pharmacological activities. Of relevant to this study, areca nut extracts inhibited antigen-induced degranulation in RBL-2H3 mast cells and the functionality of murine splenic lymphocytes and neutrophils [10-13]. Oral administration with a hydroalcoholic extract of areca nuts prevented nitroglycerine infusion-induced inflammatory responses and induced analgesic and anti-inflammatory effects in a murine hot plate model $[14,15]$. In addition, feeding rats with arecaderived polyphenols suppressed carrageenan-induced inflammatory responses and prostaglandin $E_{2}$ formation

\section{Biomed Central}

(c) 2013 Wang et al.; licensee BioMed Central Ltd. This is an Open Access article distributed under the terms of the Creative Commons Attribution License (http://creativecommons.org/licenses/by/2.0), which permits unrestricted use, distribution, and reproduction in any medium, provided the original work is properly cited. 
[16]. These reports indicate the anti-inflammatory and immunomodulatory potential of areca nut constituents. However, it remains unclear if areca-derived polyphenols affect food allergic responses.

Food allergy is an immune disorder to dietary proteins affecting up to $6 \%$ of the population in developed countries [17]. Eggs, milk, peanuts, seafood and wheat are the most common allergens known to cause food hypersensitivity [18]. Symptoms associated with food allergy may range from mild gastrointestinal discomfort to severe and life-threatening anaphylactic shock. The immunological mechanisms of food allergy require the processing and presentation of allergens by antigen-presenting cells to $\mathrm{T}$ helper (Th) cells that subsequently differentiate to the Th2 phenotype. The Th2 signature cytokine IL-4 plays a pivotal role in the pathophysiology of allergy via the induction of IgE synthesis and mast cell proliferation [19-21]. To date, avoidance of allergens is the principal way to manage food allergy. Pharmacotherapy is employed solely for relieving hypersensitivity symptoms. Hence, the development of effective strategies to prevent or treat this disorder is of great importance.

As areca nut extracts have been shown to affect the functionality of mast cells and lymphocytes that are key players involved in the pathophysiology of type I hypersensitivity, we hypothesize that areca-derived polyphenols may be effective in modulating food allergic responses. We report here the anti-allergic effect of areca-derived polyphenols administered via drinking water in a murine model of food allergy.

\section{Methods}

\section{Reagents and antibodies}

All reagents were purchased from Sigma (St. Louis, MO) unless otherwise stated. Cell culture medium and fetal bovine serum (FBS) was from Hyclone (Logan, UT). Anti-

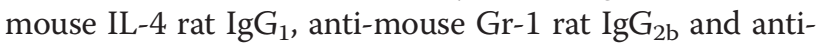
mouse IL-10 rat $\mathrm{IgG}_{2 \mathrm{~b}}$ were from BioLegend (San Diego, $\mathrm{CA})$. The anti-rat IgG secondary antibodies conjugated with alkaline phosphatase (AP) or horse radish peroxidase (HRP) were from AbCam, Inc. (Cambridge, UK).

\section{Plant material and extraction}

Fresh tender nuts of Areca catechu Linn. were directly purchased from farmer, Chiayi County, Taiwan, in March, 2009. The nuts were identified by Dr. Ih-Sheng Chen (School of Pharmacy, Kaohsiung Medical University) by comparison with a voucher specimen deposited at the Herbarium of the Department of Botany of National Taiwan University (No: TAI 152786, collected and identified by Chien-Chang Hsu on Aug 26, 1969). Polyphenolenriched areca nut extracts (PANE) were prepared as previously described [16]. Briefly, after removing the husks, the nuts were extracted three times with $80 \%$ acetone
$(1: 10 \mathrm{w} / \mathrm{v})$ and filtrated. The filtrate was evaporated to remove acetone, partitioned with $\mathrm{n}$-hexane and ethylether to remove lipids and then freeze-dried. The yield of the PANE extraction was $16 \%$. The amount of condensed tannins in PANE was $>95 \%$ as measured by the acidified vanillin method previously described [22]. The level of endotoxin in the PANE was below the detection limit (0.05 endotoxin unit/mL) using an assay kit (Kinetic$\mathrm{QCL}^{\circ}$; Lonza Walkersville Inc., Walkersville, MD).

\section{Protocol of animal experiments}

Male BALB/c mice, 5-6 weeks of age, were purchased from the Animal Breeding Center of the National Taiwan University Hospital (Taipei, Taiwan). The mice were randomized, transferred to plastic cages containing a saw-dust bedding ( $4-5$ mice per cage) and housed in a temperature $\left(23 \pm 2^{\circ} \mathrm{C}\right)$, humidity $(60 \pm 20 \%)$ and light (12-h light/dark cycle)-controlled environment. The present study employed a murine model of food allergy previously described [23]. In brief, mice were randomly divided into the following groups: naïve (NA), nonsensitized (NS), OVA-sensitized and challenged (OVA), and OVA-sensitized and challenged and PANE-treated (PANE). Mice received PANE via drinking water containing 0.05 and $0.1 \%(\mathrm{w} / \mathrm{v})$ throughout the entire treatment period. The dosing regimen was chosen according to previous reports showing the immunomodulatory activity of apple polyphenols [9] and the anti-inflammatory, hepatoprotective and immunomodulatory activities of areca nut extracts [14-16,24]. Except for the NA and NS groups, mice were sensitized with OVA by intraperitoneal injection using $0.1 \mathrm{~mL}$ sensitization solution containing $50 \mu \mathrm{g}$ OVA and $1 \mathrm{mg}$ alum on day 3 and boosted with a double dose on day 17. Serum of mice was collected prior to OVA challenge on day 31. To induce allergic responses, mice were repeatedly challenged with OVA $(50 \mathrm{mg} / 0.3 \mathrm{~mL}$ in saline/ mouse) by gavage every other day from day 31 to day 49 . Allergic diarrhea characterized as profuse liquid stool was monitored visually for $3 \mathrm{~h}$ after challenge. All mice were euthanized $3 \mathrm{~h}$ after the last OVA challenge and the spleen and duodenum were harvested for further experimentation. The animal experiments were approved by the Institutional Animal Care and Use Committee of the National Taiwan University.

\section{Spleen index}

The spleen of each mouse was dissected out and weighed immediately after sacrifice. The spleen index was calculated as the spleen weight $(\mathrm{mg})$ per body weight $(\mathrm{g})$.

\section{Cellularity of splenocytes}

Splenocytes were stained with rat anti-mouse CD4 and Gr-1 conjugated with FITC, and rat anti-mouse CD8, CD11b, B220 conjugated with PE-Cy5 antibodies (BioLegend, 
San Diego, CA) in PBS containing 2\% FBS. After washing, the single cell fluorescence of 10,000 cells for each sample was measured by a flow cytometer (BD FACSCalibur, San Jose, CA). Data were analyzed using the software Flowjo 5.7.

\section{Histological examination of duodenum}

The duodenum was excised and fixed in $10 \%$ neutral buffered formalin for 2 days. Tissue were embedded in paraffin, sectioned at a thickness of 4-5 $\mu \mathrm{m}$ and stained with hematoxylin and eosin (H\&E) for routine histopathology. The ratio of villi length over crypt depth was measured by Image-Pro Plus 5.1 morphometric analysis software (Media Cybernetics, Inc. Rockville, MD). Tissue sections were also stained with toluidine blue for identification of mast cells. The number of total and degranulated mast cells was counted manually.

\section{Enzyme-linked immunosorbent assay (ELISA) for antibody measurement}

The levels of total and OVA-specific IgE in serum samples were measured by ELISA [25].

\section{Immunohistochemical staining}

Tissue sections were deparaffinized and then rehydrated following a standard procedure. The rehydrated slides were immersed in Trilogy ${ }^{\mathrm{mm}}$ (Cell Marque, Hot Springs, $\mathrm{AR})$ at $121^{\circ} \mathrm{C}$ for $15 \mathrm{~min}$ for antigen retrieval. The endogenous peroxidase activity was then quenched with $3 \% \mathrm{H}_{2} \mathrm{O}_{2}$ in methanol and blocked with normal goat serum. Primary antibodies were applied onto each section overnight. The slides were treated with super enhancer, and then incubated with poly-HRP reagent. For visualization, the slides were treated with the peroxidase substrate 3-amino-9ethylcarbazole (AEC) for 2 min followed by hematoxylin counter staining (blue color). For IHC double staining, AEC-treated slides were incubated with another primary antibody at $4{ }^{\circ} \mathrm{C}$ in the dark overnight followed by incubation with AP-conjugated secondary antibody for $1 \mathrm{~h}$. The slides were then treated with AP substrate, 5-bromo-4chloro-3-indolyl phosphate/nitroblue tetrazolium (BCIP/ NBT), for 30 min for observation of a second staining without counter-staining. The number of IHC-positive signals was quantified using the Image Pro Plus 5.1 program. The number of double positive cells showing dark blue surrounded with red color was counted manually. Six duodenums per group were analyzed at 200 -fold magnification.

\section{Statistical analysis}

Data of diarrhea occurrence were expressed as percentage and analyzed by the Chi-square test to compare the difference between PANE-treated groups and the OVA control. All other data are expressed as the mean \pm standard error (SE) for each treatment group in the individual experiments. Normality and homoscedasticity of data were tested by the Shapiro-Wilk test and the Bartlett's test, respectively. Analysis of variance was performed by one-way ANOVA. Dunnett's two-tailed $t$-test was used to compare treatment groups to the control group. $P$ value $<0.05$ was defined as statistical significance.

\section{Results}

PANE did not affect body weight, and the spleen index and cellularity

We firstly investigated whether administration of PANE via drinking water influenced the spleen index and cellularity in mice with food allergy. As shown in Table 1, oral intake of PANE $(0.05 \%$ and $0.1 \%)$ did not affect the body weight, the spleen index and the population of splenic $\mathrm{CD} 4^{+}, \mathrm{CD} 8^{+}, \mathrm{B} 220^{+}$and $\mathrm{CD} 11 \mathrm{~b}^{+}$cells.

Table 1 No effect of PANE on the body weight, and the spleen index and cellularity in mice with food allergy

\begin{tabular}{|c|c|c|c|c|c|}
\hline & \multirow[t]{2}{*}{ NA } & \multirow[t]{2}{*}{ NS } & \multirow[t]{2}{*}{ OVA } & \multicolumn{2}{|c|}{ PANE } \\
\hline & & & & $0.05 \%$ & $0.1 \%$ \\
\hline \multicolumn{6}{|l|}{ Body weight (g) } \\
\hline Day 1 & $24.5 \pm 0.8$ & $24.1 \pm 0.7$ & $23.9 \pm 0.5$ & $25.0 \pm 0.7$ & $24.4 \pm 0.6$ \\
\hline Day 49 & $28.6 \pm 0.5$ & $27.5 \pm 0.5$ & $27.4 \pm 0.4$ & $27.4 \pm 0.7$ & $27.1 \pm 0.5$ \\
\hline Spleen weight (mg) & $88.4 \pm 3.5$ & $84.9 \pm 4.5$ & $91.0 \pm 2.8$ & $87.6 \pm 3.6$ & $93.0 \pm 2.7$ \\
\hline Spleen index & $3.0 \pm 0.1$ & $3.0 \pm 0.1$ & $3.2 \pm 0.1$ & $3.1 \pm 0.1$ & $3.3 \pm 0.1$ \\
\hline \multicolumn{6}{|l|}{ Spleen cellularity (\%) } \\
\hline $\mathrm{CD}^{+}$ & $26.4 \pm 0.2$ & $26.7 \pm 0.8$ & $25.6 \pm 1.2$ & $25.7 \pm 1.3$ & $26.0 \pm 1.4$ \\
\hline $\mathrm{CD}^{+}$ & $10.6 \pm 0.4$ & $11.0 \pm 0.6$ & $11.0 \pm 0.3$ & $11.5 \pm 0.6$ & $10.6 \pm 0.5$ \\
\hline $\mathrm{B} 22 \mathrm{O}^{+}$ & $55.1 \pm 1.5$ & $55.2 \pm 1.9$ & $55.8 \pm 3.5$ & $55.5 \pm 2.6$ & $56.6 \pm 3.3$ \\
\hline$C D 11 b^{+}$ & $4.2 \pm 0.4$ & $4.9 \pm 0.2$ & $4.3 \pm 0.1$ & $4.3 \pm 0.1$ & $4.4 \pm 0.3$ \\
\hline
\end{tabular}

Mice were treated with PANE as described in Figure 2. The spleen index was calculated as the spleen weight (mg) per body weight (g). Splenocytes were stained for CD4, CD8, B220 and CD11b and analyzed by flow cytometry. Data are expressed as mean \pm SE of 11 samples per group pooled from 3 independent experiments. 


\section{PANE attenuated the occurrence of allergic diarrhea} We next investigated the effect of PANE on OVA challenge-induced diarrhea that is a hallmark of food allergic reactions. Repeated OVA challenge gradually induced diarrhea and all of the mice in the OVA group developed diarrhea after the 7th OVA challenge (Figure 1). The high dose of PANE (0.1\%) markedly attenuated the incidence of diarrhea from the 5th to the last OVA challenge, in which the rate of diarrhea from the 8th and 10th OVA challenge was reduced from $100 \%$ to $40 \%$ (Figure 1). The induction of allergic diarrhea in mice receiving $0.05 \%$ PANE was also significantly attenuated from the 6th to the 8th OVA challenge (Figure 1).

PANE attenuated intestinal inflammation and mast cells infiltration and degranulation

We further examined the histological changes associated with food allergy in the duodenum using H\&E staining. Compared to the normal morphology in the NS group, the shape of the villus was irregular and short, and the crypt was heavily infiltrated with inflammatory cells in the

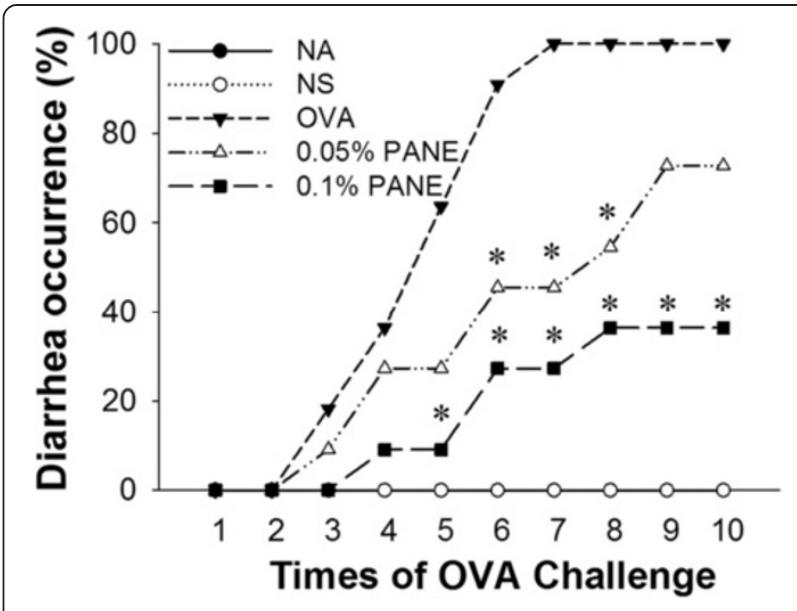

Figure 1 PANE attenuated the occurrence of allergic diarrhea. Mice were treated as the protocol described in the Methods section. Allergic diarrhea was monitored visually for $3 \mathrm{~h}$ after OVA challenge. Mice with profuse liquid stool were identified as diarrhea-positive animals. Data are pooled from 3 independent experiments $(n=11$ per group). ., $p<0.05$ compared to the OVA group.

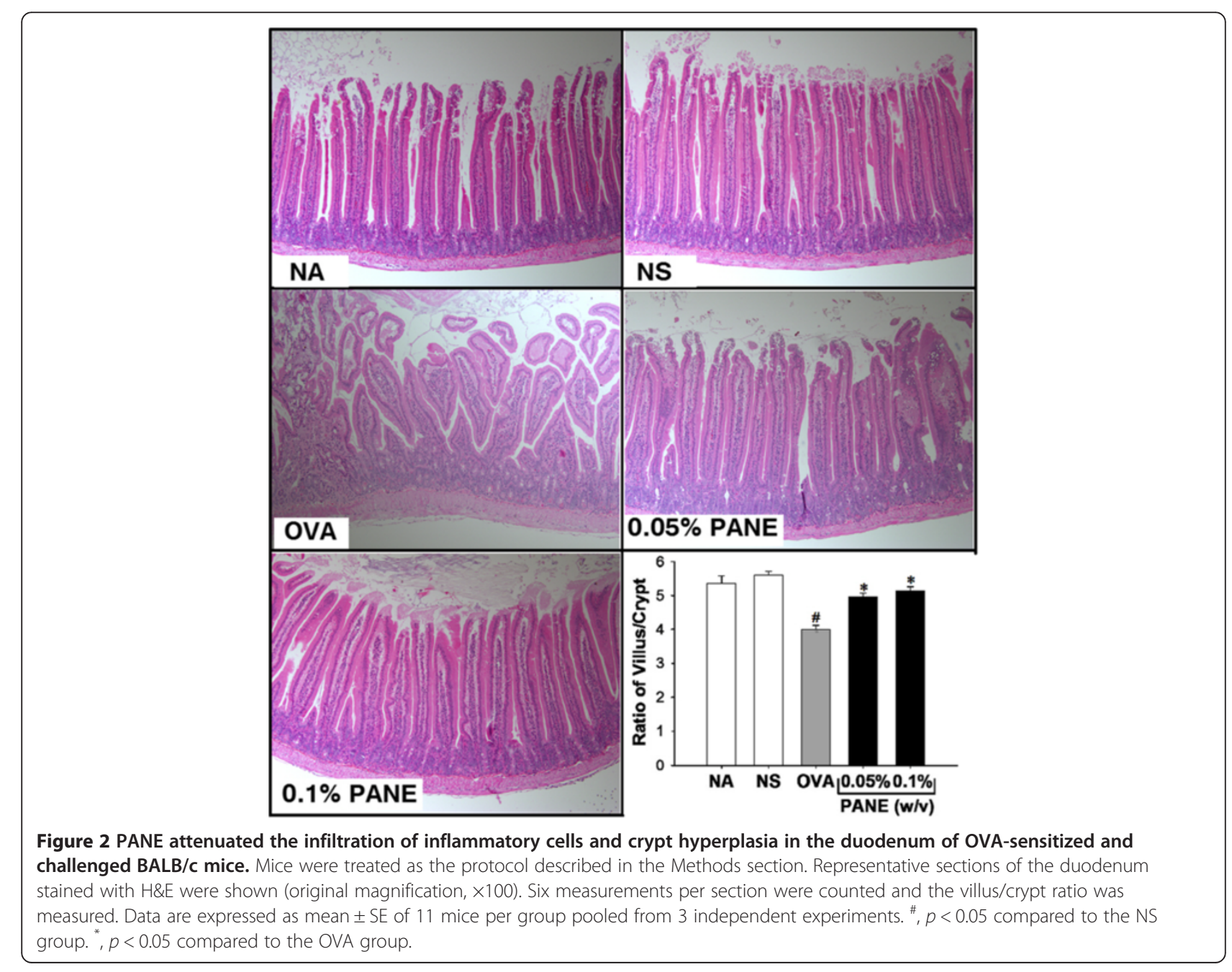


OVA group, demonstrating strong inflammatory reactions with a reduced villus/crypt ratio associated with food allergy (Figure 2; OVA vs. NS). Notably, both doses of PANE prevented the morphological alterations, and restored the reduced villus/crypt ratio in allergic mice (Figure 2; PANE vs. OVA). The infiltration and degranulation of mast cells were examined using toluidine blue staining. As shown in Figure 3, both doses of PANE significantly attenuated mast cell infiltration and degranulation in the duodenum of OVA-sensitized and challenged mice.

\section{PANE attenuated the production of $\lg E$}

Mast cells armed with allergen-specific IgE are the effector cells to initiate hypersensitivity responses. We therefore examined if PANE affected the production of total and OVA-specific IgE. A marked increase in the serum level of total and OVA-specific IgE in the OVA group was observed (Table 2; OVA vs. NA), which was significantly attenuated in mice treated with both doses of PANE (Table 2).
PANE attenuated Th2 responses and induced myeloidderived suppressor cells

We investigated whether PANE affected the expression of IL-4 in the duodenum of allergic mice. Results from IHC staining showed that PANE attenuated the expression of IL- $4^{+}$cells in the duodenum (Figure 4), whereas the number of IFN $-\gamma^{+}$cells was not altered (data not shown). To further address the potential mechanisms for ANE-mediated anti-allergic effects, we examined whether PANE affected the induction of myeloid-dericed suppressor cells (MDSC) in mice with food allergy. The number of $\mathrm{Gr}-1^{+}, \mathrm{IL}-10^{+}$and $\mathrm{Gr}-1^{+} \mathrm{IL}-10^{+}$cells was scarce in the NS and OVA groups. Oral intake of PANE significantly increased the number of $\mathrm{Gr}-1^{+}, \mathrm{IL}-10^{+}$and $\mathrm{Gr}-1^{+} \mathrm{IL}-10^{+}$ cells in the duodenum, as compared to the $\mathrm{VH}$ control group (Figure 5; Table 3).

\section{Discussion}

Although Arecae semen has been used as a traditional Chinese medicine for centuries to treat certain gastrointestinal disorders such as diarrhea [1], it remains

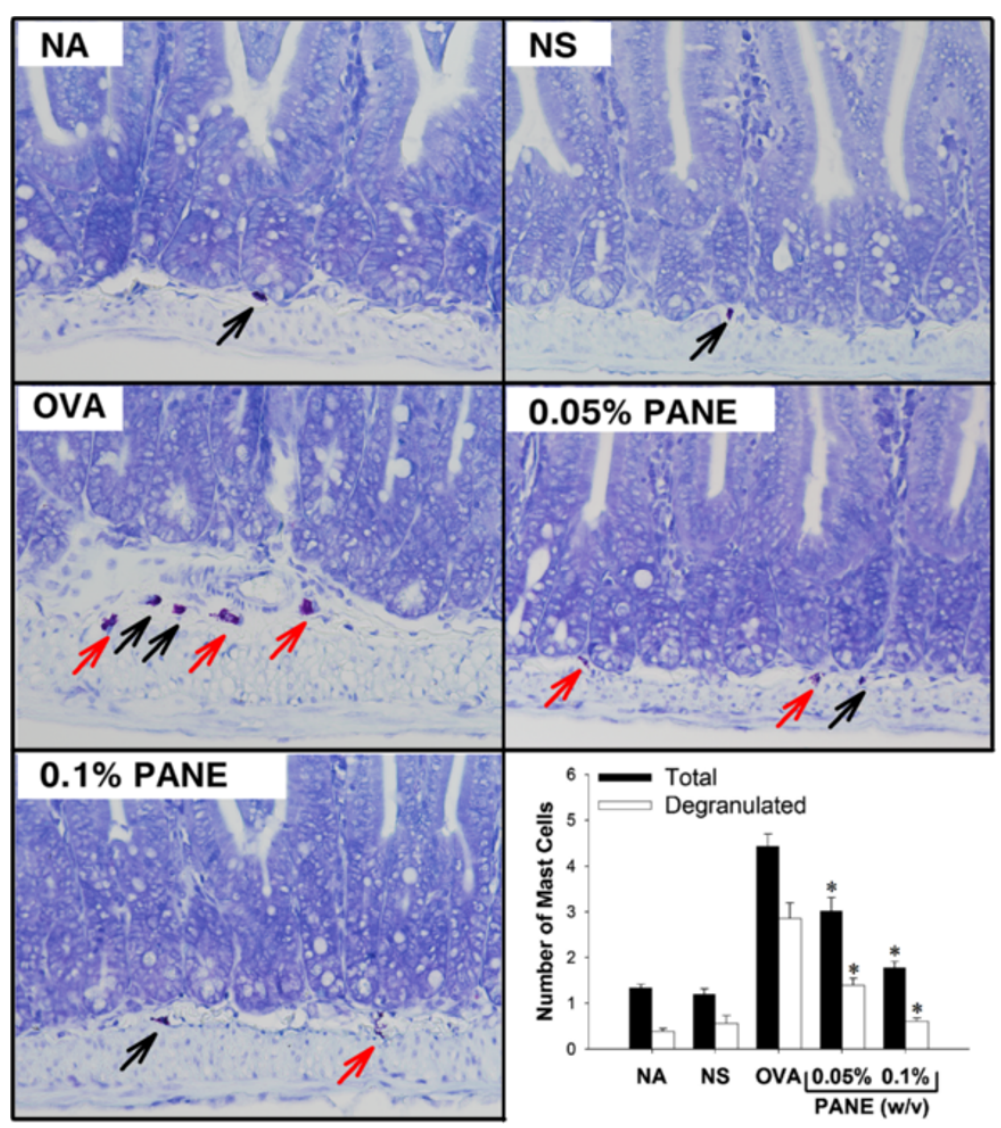

Figure 3 PANE attenuated the infiltration and degranulation of mast cells in the duodenum. Tissue sections of the duodenum were stained with toluidine blue. (A) Representative sections of the duodenum were shown (original magnification, $\times 400$ ). Black and red arrows indicate non-degranulated and degranulated mast cells, respectively. (B) The number of total and degranulated mast cells was counted manually. Three measurements per section were counted. Data are expressed as mean \pm SE of 11 samples per group pooled from 3 independent experiments. ${ }^{*}, p<0.05$ compared to the OVA group. 
Table 2 PANE attenuated the production of serum total and OVA-specific IgE

\begin{tabular}{ccc}
\hline Group & Total lgE $(\mathbf{n g} / \mathbf{m L})$ & OVA-lgE (O.D.) \\
\hline NA & $211.01 \pm 38.38$ & $0.02 \pm 0.00$ \\
NS & $286.83 \pm 15.55$ & $0.01 \pm 0.00$ \\
OVA & $4011.59 \pm 667.01^{\#}$ & $0.25 \pm 0.06^{\#}$ \\
$0.05 \%$ PANE & $2488.36 \pm 356.68^{*}$ & $0.11 \pm 0.02^{*}$ \\
$0.1 \%$ PANE & $1956.17 \pm 381.27^{*}$ & $0.10 \pm 0.02^{*}$ \\
\hline
\end{tabular}

Data are expressed as the mean \pm SE of 11 samples pooled from 3 independent experiments. ${ }^{\#}, p<0.05$ compared to the NS group. ${ }^{*}, p<0.05$ compared to the OVA group.

unclear if areca-derived constituents affect allergic diarrhea associated with food allergy. As areca nuts contain a rich amount of polyphenols which have been documented to possess immunomodulatory and anti-allergic properties $[8,9]$, the present study aims to investigate the potential effect of areca polyphenols on food allergy. Our results demonstrated that oral intake of PANE attenuated intestinal inflammation, mast cell activation and the occurrence of allergic diarrhea. To the best of our knowledge, these data provide the first evidence to show the anti-food allergic effects of areca-derived polyphenols.

Areca-derived polyphenols contain monomers of $(+)$-catechin and (-)-epicatechin and their polymerized oligomers that are structurally similar to apple-derived procyanidins $[6,16]$. Procyanidins are the second most abundant group of natural phenolics widely distributed in the plant kingdom [7-9]. The health-promoting potential of procyanidins has attracted a great deal of attention. Notably, previous studies reported that oral intake of apple procyanidins attenuated atopic dermatitis, food allergy and inflammatory colitis $[8,9]$. Together with the present results, it is suggested that both apple- and arecaderived procyanidins are functional phytochemicals with potential anti-allergic properties.

The present data showed that oral intake of PANE possess anti-inflammatory activities against food allergy; on the contrary, intraperitoneal injection of PANE induced pro-inflammatory responses [26]. Previous studies

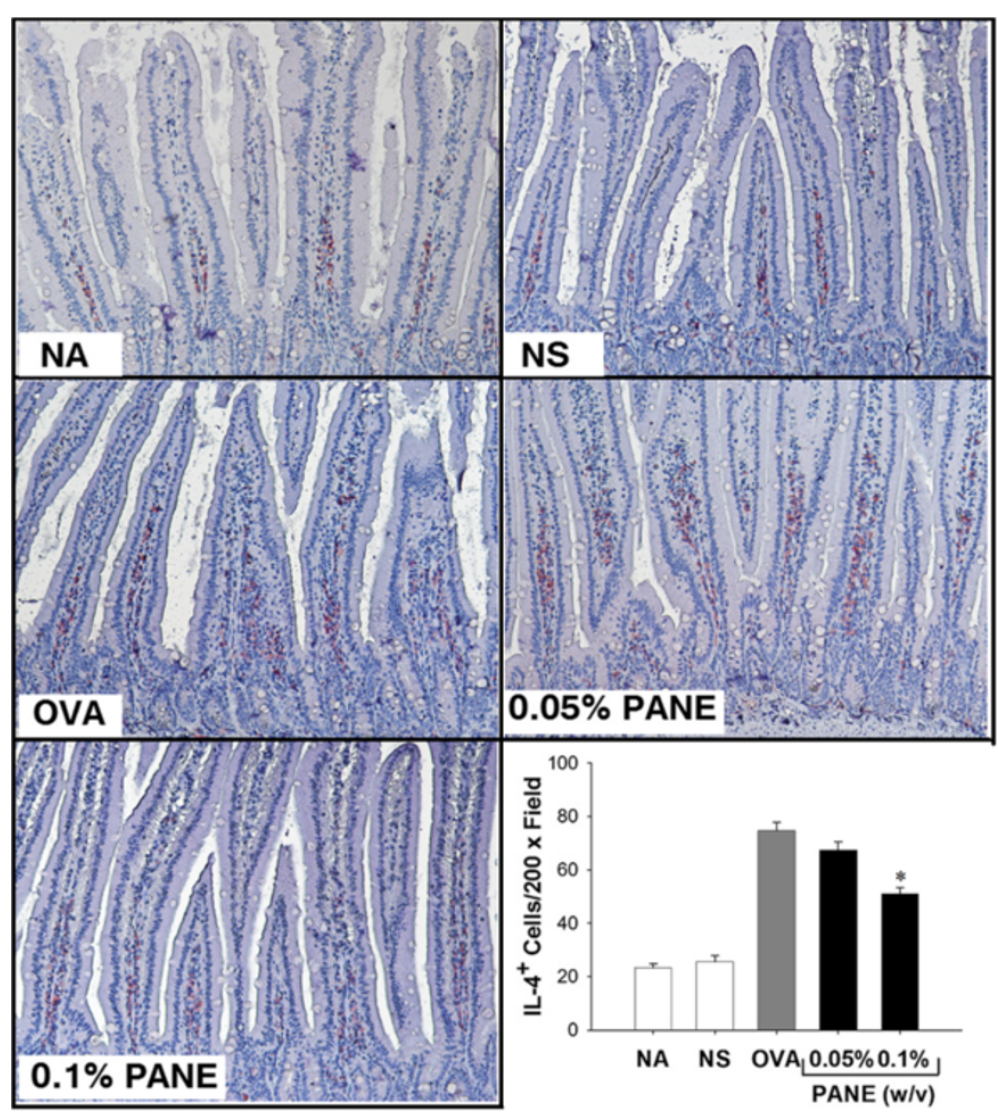

Figure 4 PANE reduced the number of IL-4+ cells in the duodenum. Mice were treated as the protocol described in the Methods section. The expression of IL-4 in the duodenum was examined using IHC staining. Representative sections stained with IL-4 were shown (original magnification, x200). Cells with red signals around the blue nuclei indicate the IL-4 positive cells. Six measurements per section were counted. Data are expressed as the mean \pm SE of 11 samples per group pooled from 3 independent experiments. ${ }^{*}, p<0.05$ compared to the VH group. 


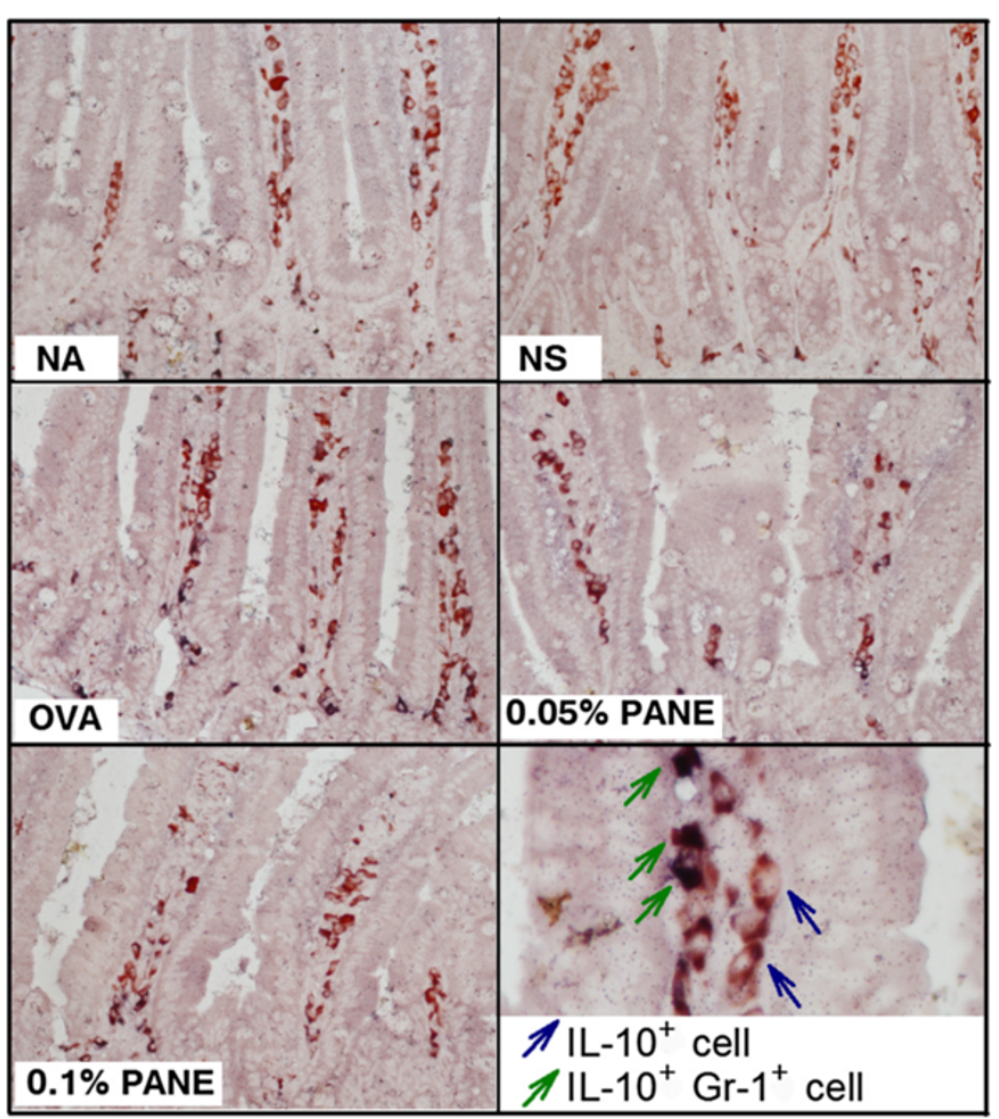

Figure 5 PANE increased the number of $\mathrm{Gr}-1^{+} \mathrm{IL}-10^{+}$cells in the duodenum. Mice were treated as the protocol described in the Methods section. Representative sections stained for Gr-1 and IL-10 are shown (original magnification, $\times 200$ ). Cells with blue arrows indicate IL-10+ cells. Green arrows indicate $\mathrm{Gr}-1^{+} \mathrm{LL}-10^{+}$cells showing red signals around the dark blue nuclei. Quantitative data are shown in Table 3.

showed that procyanidins can be absorbed and detected in the plasma after oral uptake [27,28]. The complex linkage and the mean degree of polymerization (mDP) of procyanidins may affect their absorption, bioavailability and metabolism [29]. For example, the rate of absorption of monomeric to trimeric procyanidins from the gut was 10 times greater than that of highly oligomeric procyanidins $(\mathrm{mDP}>6)[30]$, which are poorly absorbed in the gut and

Table 3 PANE induced Gr- $1^{+}$and $\mathrm{Gr}-1^{+} \mathrm{IL}-10^{+}$cells in the duodenum of allergic mice

\begin{tabular}{lccccc}
\hline & \multicolumn{4}{c}{ Number of positive cells ${ }^{\boldsymbol{a}}$} \\
\cline { 2 - 6 } & NA & NS & OVA & \multicolumn{2}{c}{ PANE } \\
\cline { 3 - 6 } & & & $\mathbf{0 . 0 5 \%}$ & $\mathbf{0 . 1 \%}$ \\
\hline $\mathrm{Gr}-1^{+}$ & $2 \pm 0$ & $2 \pm 0$ & $2 \pm 0$ & $2 \pm 0$ & $\mathbf{4} \pm \mathbf{0}^{*}$ \\
$\mathrm{IL}-10^{+}$ & $13 \pm 1$ & $15 \pm 2$ & $24 \pm 2^{\#}$ & $\mathbf{2 9} \pm \mathbf{2}^{*}$ & $\mathbf{3 1} \pm \mathbf{2}^{*}$ \\
$\mathrm{Gr}-1^{+} \mathrm{IL}-10^{+}$ & $1 \pm 0$ & $2 \pm 0$ & $2 \pm 0$ & $2 \pm 0$ & $\mathbf{3} \pm \mathbf{0}^{*}$ \\
\hline
\end{tabular}

${ }^{a}$ The number of single positive cells was quantified using the software ImagePro Plus 5.1, and double positive cells were counted manually. Data are expressed as mean \pm SEM $(\mathrm{n}=6) .{ }^{\#}, p<0.05$ compared to the NS group. ${ }^{*}, p<0.05$ compared to the OVA group. Results are a representative of 3 independent experiments. largely reach the colon where they can be degraded into various metabolites by the microflora [31]. Hence, we speculate that the oligomeric procyanidins with high chain-length can enter the systemic circulation system by intraperitoneal injection, while monomer to trimmers may be the major constituents absorbed into the bloodstream after oral administration of PANE. We assumed that the contrasting anti- and pro-inflammatory effects between the present and previous results may be due to the different absorption profile of PANE constituents between oral and intraperitoneal administrations. Further studies are required to address this issue.

We previously reported that intraperitoneal administration of PANE enhanced Th1 cell-mediated immunity and induced the development of myeloid-derived suppressor cells (MDSC) in a murine model of delayed-type hypersensitivity [26]. MDSC have been shown to regulate T-cell homeostasis under various pathophysiological conditions, such as inflammation or cancers [32]. The generation of MDSC is suggested to improve survival associated with graft transplantation by suppressing alloantigen-reactive 
T-cell reactivity [33]. Moreover, adoptive transfer of MDSC dampened allergen-induced airway inflammation in an IL-10-dependent manner [34]. MDSC may produce IL-10 to promote the generation of regulatory T cells and suppress the expression of FceRI and the activation of mast cells to prevent excessive inflammation $[35,36]$. To date, it remains mostly unknown if MDSC play a role in allergic responses. In the present study, we demonstrated that PANE increased the infiltration of IL-10-producing MDSC in the intestine of mice with food allergy. These results suggest that MDSC may be involved in the regulation of the gut immunobalance, and the anti-allergic effect of PANE may be mediated, at least in part, by the induction of MDSC.

Lamina propria cells consist of approximately $2-3 \%$ of mast cells in normal gastrointestinal mucosa, which can augment up to tenfold in disease conditions [37]. Mast cells express high-affinity IgE receptors to bind IgE; reexposure of allergen triggers the release of inflammatory mediators via crosslinking of surface-bound IgE receptors [38]. Therefore, inhibition of mast cell activation and degranulation is a strategy for managing allergy. Previous studies reported an inhibitory effect of areca nut extracts on mast cell functions in vitro [10]. Our data further demonstrated the suppressive effect of PANE on mast cell infiltration and degranulation in mice with food allergy. Furthermore, the serum level of OVA-specific IgE was attenuated by PANE, indicating that PANE downregulated the function of mast cells and IgE synthesis leading to the attenuation of intestinal inflammation.

\section{Conclusion}

In conclusion, the present study demonstrated the antifood allergic properties of PANE administered via drinking water in the employed murine model of food allergy. The anti-allergic effect of PANE was associated with the suppression of Th2 immunity and the induction of MDSC in the inflamed site. These data provide evidence to substantiate some of the claimed beneficial effects of Arecae semen, in particular anti-diarrhea. The potential of arecaderived polyphenols as functional phytochemicals against food allergy warrants further investigation.

\section{Competing interests}

The authors declared that they have no competing interests.

\section{Authors' contributions}

CCW carried out experiments and participated in the analysis of data. YRL carried out experiments. MHL supervised animal experiments and participated in the preparation of the manuscript. TRJ designed the study, supervised experiments and refined the manuscript for publication. All authors read and approved the final manuscript.

\section{Acknowledgments}

We thank Prof. Ih-Sheng Chen (School of Pharmacy, Kaohsiung Medical University) for his helpful assistance to the identification of plant material and the critical comments for revising this manuscript. This work was supported by grants NSC101-2320-B-037-001 from the National Science
Council, Executive Yuan (Taipei, Taiwan) and KMU-Q110004, KMU-Q102013 and KMU-ER013 from Kaohsiung Medical University Research Foundation (Kaohsiung City, Taiwan).

\section{Author details}

'School of Pharmacy, Kaohsiung Medical University, No. 100, Shih-Chuan 1st Road, 807, Kaohsiung, Taiwan. ${ }^{2}$ Department and Graduate Institute of Veterinary Medicine, School of Veterinary Medicine, National Taiwan University, No. 1, Section 4, Roosevelt Road, 106 Taipei, Taiwan.

${ }^{3}$ Radiopharmaceuticals Production and Marketing Center, Institute of Nuclear Energy Research, No. 1000 Wenhua Road, Jiaan Village, 325, Longtan

Township, Taoyuan, Taiwan.

Received: 13 February 2013 Accepted: 18 June 2013

Published: 2 July 2013

\section{References}

1. Duke JA, Bogenschutz-Godwin MJ: Handbook of medicinal herbs. 2nd edition. Boca Raton: CRC Press LLC; 2002:72.

2. Nadkarni KM: Indian materia medica. 3rd edition. Bombay: Popular Prakashan; 1976:130-133.

3. Bingshan $\mathrm{H}$, Yuxia W: Thousand formulas and thousand herbs of traditional chinese medicine, Volume 2. Harbin: Heilongjiang Education Press; 1993.

4. Nonaka G, Hsu FL, Nishioka I: Structures of dimeric, trimeric, and tetrameric procyanidins from Areca catechu L. J Chem Soc Chem Commun 1981:781-783

5. Mathew AG, Govindarajan VS: Polyphenolic substances of arecanut. II. Changes during maturation and ripening. Phytochemistry 1964, 3:657-665.

6. Wu Q, Yang Y, Simon JE: Qualitative and quantitative HPLC/MS determination of proanthocyanidins in areca nut (Areca catechu). Chem Biodivers 2007, 4(12):2817-2826.

7. D'Archivio M, Filesi C, Di Benedetto R, Gargiulo R, Giovannini C, Masella R: Polyphenols, dietary sources and bioavailability. Ann Ist Super Sanita 2007, 43(4):348-361.

8. Yoshioka Y, Akiyama H, Nakano M, Shoji T, Kanda T, Ohtake Y, Takita T, Matsuda R, Maitani T: Orally administered apple procyanidins protect against experimental inflammatory bowel disease in mice. Int Immunopharmacol 2008, 8(13-14):1802-1807.

9. Akiyama H, Sato Y, Watanabe T, Nagaoka MH, Yoshioka Y, Shoji T, Kanda T, Yamada K, Totsuka M, Teshima R, et al: Dietary unripe apple polyphenol inhibits the development of food allergies in murine models. FEBS Lett 2005, 579(20):4485-4491.

10. Lee JH, Chang SH, Park YS, Her E, Lee HY, Park JW, Han JW, Kim YM, Choi WS: In-vitro and in-vivo anti-allergic actions of Arecae semen. J Pharm Pharmacol 2004, 56(7):927-933.

11. Wang CC, Liu TY, Wey SP, Wang Fl, Jan TR: Areca nut extract suppresses T-cell activation and interferon-gamma production via the induction of oxidative stress. Food Chem Toxicol 2007, 45(8):1410-1418.

12. Lai YL, Lin JC, Yang SF, Liu TY, Hung SL: Areca nut extracts reduce the intracellular reactive oxygen species and release of myeloperoxidase by human polymorphonuclear leukocytes. J Periodontol Res 2007, 42(1):69-76.

13. Hung SL, Lee YY, Liu TY, Peng JL, Cheng YY, Chen YT: Modulation of phagocytosis, chemotaxis, and adhesion of neutrophils by areca nut extracts. J Periodontol 2006, 77(4):579-585.

14. Pithayanukul P, Nithitanakool S, Bavovada R: Hepatoprotective potential of extracts from seeds of Areca catechu and nutgalls of Quercus infectoria. Molecules 2009, 14(12):4987-5000.

15. Bhandare AM, Kshirsagar AD, Vyawahare NS, Hadambar AA, Thorve VS: Potential analgesic, anti-inflammatory and antioxidant activities of hydroalcoholic extract of Areca catechu L nut. Food Chem Toxicol 2010, 48(12):3412-3417.

16. Huang PL, Chi CW, Liu TY: Effects of Areca catechu L. containing procyanidins on cyclooxygenase-2 expression in vitro and in vivo. Food Chem Toxicol 2010, 48(1):306-313.

17. Mermelstein NH: Food allergies and other food sensitivities. ASDC J Dent Child 2001, 53(4):296

18. Bush RK, Hefle SL: Food allergens. Crit Rev Food Sci Nutr 1996, 36:S119-S163.

19. Tepper RI, Levinson DA, Stanger BZ, Campos-Torres J, Abbas AK, Leder P: IL-4 induces allergic-like inflammatory disease and alters T cell development in transgenic mice. Cell 1990, 62(3):457-467.

20. Bohle B: T lymphocytes and food allergy. Mol Nutr Food Res 2004, 48(6):424-433. 
21. Lin XP, Magnusson J, Ahlstedt S, Dahlman-Hoglund A, Hanson LA, Magnusson O, Bengtsson U, Telemo E: Local allergic reaction in food-hypersensitive adults despite a lack of systemic food-specific lgE. J Allergy Clin Immunol 2002, 109(5):879-887.

22. Broadhurst RB, Jones WT: Analysis of condensed tannins using acidified vanillin. J Sci Food Agr 1978, 29(9):788-794.

23. Brandt EB, Strait RT, Hershko D, Wang Q, Muntel EE, Scribner TA, Zimmermann N, Finkelman FD, Rothenberg ME: Mast cells are required for experimental oral allergen-induced diarrhea. J Clin Invest 2003, 112(11):1666-1677.

24. Wang CC, Deng MC, Jan TR: Areca nut extracts attenuated interferon- $\gamma$ and antigen-specific lgM production in BALB/c Mice. J Food Drug Anal 2011, 19(3):252-258.

25. Jan T, Wey S, Kuan C, Liao M, Wu H: Diosgenin, a steroidal sapogenin, enhances antigen-specific $\lg _{2 a}$ and interferon-gamma expression in ovalbumin-sensitized BALB/c Mice. Planta Med 2007, 73(5):421.

26. Wang $C C$, Lin $H L$, Liang HJ, Jan TR: Areca nut extracts enhance the development of $\mathrm{CD} 11 \mathrm{~b}^{+} \mathrm{Gr}-1^{+}$cells with the characteristics of myeloid derived suppressor cells in antigen stimulated mice. J Oral Pathol Med 2011, 40(10):769-777.

27. Baba S, Osakabe N, Natsume M, Terao J: Absorption and urinary excretion of procyanidin B2 [epicatechin-(4beta-8)-epicatechin] in rats. Free Radic Biol Med 2002, 33(1):142-148

28. Sano A, Yamakoshi J, Tokutake S, Tobe K, Kubota Y, Kikuchi M: Procyanidin $B 1$ is detected in human serum after intake of proanthocyanidin-rich grape seed extract. Biosci Biotech Biochem 2003, 67(5):1140-1143.

29. Lotito SB, Actis-Goretta L, Renart ML, Caligiuri M, Rein D, Schmitz HH, Steinberg FM, Keen CL, Fraga CG: Influence of oligomer chain length on the antioxidant activity of procyanidins. Biochem Biophys Res Commun 2000, 276(3):945-951.

30. Deprez S, Mila I, Huneau JF, Tome D, Scalbert A: Transport of proanthocyanidin dimer, trimer, and polymer across monolayers of human intestinal epithelial Caco-2 cells. Antioxid Redox Signal 2001, 3(6):957-967.

31. Deprez S, Brezillon C, Rabot S, Philippe C, Mila I, Lapierre C, Scalbert A: Polymeric proanthocyanidins are catabolized by human colonic microflora into low-molecular-weight phenolic acids. J Nutr 2000, 130(11):2733-2738.

32. Ostrand-Rosenberg S, Sinha P: Myeloid-derived suppressor cells: linking inflammation and cancer. J Immunol 2009, 182(8):4499-4506.

33. Dugast AS, Haudebourg T, Coulon F, Heslan M, Haspot F, Poirier N, Vuillefroy De Silly R, Usal C, Smit H, Martinet B: Myeloid-derived suppressor cells accumulate in kidney allograft tolerance and specifically suppress effector T cell expansion. J Immunol 2008, 180(12):7898.

34. Arora M, Poe SL, Oriss TB, Krishnamoorthy N, Yarlagadda M, Wenzel SE, Billiar TR, Ray A, Ray P: TLR4/MyD88-induced CD $11^{+} \mathrm{Gr}-1^{\text {int }} \mathrm{F} 4 / 80^{+}$nonmigratory myeloid cells suppress Th2 effector function in the lung. Mucosal Immunol 2010, 3(6):578-593.

35. Gabrilovich DI, Nagaraj S: Myeloid-derived suppressor cells as regulators of the immune system. Nat Rev Immunol 2009, 9(3):162-174.

36. Kennedy PG: Cytokines in central nervous system trypanosomiasis: cause, effect or both? Trans R Soc Trop Med Hyg 2009, 103(3):213-214.

37. Bischoff SC, Wedemeyer J, Herrmann A, Meier PN, Trautwein C, Cetin Y, Maschek H, Stolte M, Gebel M, Manns MP: Quantitative assessment of intestinal eosinophils and mast cells in inflammatory bowel disease. Histopathology 1996, 28(1):1-13.

\section{Submit your next manuscript to BioMed Central and take full advantage of:}

- Convenient online submission

- Thorough peer review

- No space constraints or color figure charges

- Immediate publication on acceptance

- Inclusion in PubMed, CAS, Scopus and Google Scholar

- Research which is freely available for redistribution

Submit your manuscript at www.biomedcentral.com/submit
Ciomed Central 